\title{
Beating the Brush for Books: The Dealers' Sources of Supply
}

\author{
BY HAROLD J. MASON
}

IN A RECENT ARTICLE in another library I journal $^{1}$ I made the point that American periodicals dealers have surprisingly and, from the standpoint of good business principle, foolishly avoided telling their clientele anything about themselves. I stated that it is my great hope that the dealers themselves would correct this situation within the near future. Certainly, I should think, the librarians in this country would aid and expedite this correction by their natural curiosity about an area of acquisitions in which they are currently spending millions of dollars.

I distinguish periodicals dealers from subscription agents and book dealers as those companies which buy, stock, and sell back-files of predominantly outof-print general and scholarly journals. A large periodicals company will maintain sets, volumes, and issues of publications ranging over such diverse subject areas as geography (Annals of the Association of American Geographers), history (American Historical Review), medicine (American Journal of Clinical Pathology), law (Columbia Law Review), engineering (Translations of the American Society of Civil Engineers), zoology (Proceedings of the Zoological Society of London), geology (Economic Geology), philology (Modern Language Notes), botany (Botanical Review), chemistry (Journal of Physical Chemistry), physics (British Journal of Applied Physics), and literature (American Literature), to mention some examples.

1 "Periodical Sets and the World Market; or, Life in a Rubber-Boot Factory" Library Resources and Technical Services, IV (1960), 295.302.
Mr. Mason is Assistant Manager, Kraus Periodicals, Inc., New York, N. Y.

In that earlier article, within the limited amount of space available, I traced only the outlines of the activities and functions of the American periodicals dealer. In this and a subsequent paper the two most important specifics of the methods by which we buy and sell periodicals will be discussed.

\section{Buying-Methods}

Involved as we are in a commodity that runs in numbers to millions of individual pieces, one must have an extensive knowledge of the periodicals market before he is allowed, in our company, to do much buying. There is, after all, entirely too much room for error. The figure "millions" is no exaggeration. A good sized periodicals firm (and you can count the number of such firms on the fingers of one hand) stocks well over 7,500 individual titles. Each of these titles is composed of a specific number of volumes-ranging from 257 volumes in the case of the American Journal of Science which began publication in 1818 , to 5 volumes for the Journal of the American Institute of Chemical Engineers which only began in 1955 . Then again, each volume is composed of a given number of issues-12 per volume for the earlier publication, 4 per volume for the latter. Add to all this the fact that each volume has a title-page-index, which is also counted as "a piece," and it is not diffcult to arrive at a figure of "millions" of items. 
The importance in citing these figures (and a million of anything is still a lot of anything even in these days of billions and trillions) is to show the enormity of our field of operations. For the fact is that literally every issue within every volume of all the thousands of periodical titles that we handle is individually identifiable as to importance (with regard to subject matter) and scarcity (with regard to the possibility of its acquisition). To take an example, we need go no further than the very common (i.e. easily available, because it is printed in such a huge edition) Analytical Chemistry, published by the American Chemical Society. This is a title which, because of its "commonness," for years could not be given away. An examination of our various catalogs will show that the price (contrary to the general rise in prices of other journals) has consistently fallen for certain volumes-from $\$ 5.00$ to $\$ 4.00$ to $\$ 3.00$ to its present $\$ 2.50$ each. Yet within the 30 published volumes of $\mathrm{Ana}$ lytical Chemistry we have have found that one issue, volume 6 number 3 , has been virtually impossible to find on the second-hand market. The same is true of Econometrica volume 17 number 1, Southwestern Journal of Anthropology volume 12 number 2, French Review volume 2 number 1, Bulletin of Mathematical Biophysics volume 1 number 1 , Journal of the History of Medicine volume 6 number 2, Journal of General Education volume 1 numbers 1 through 3 , and a hundred other cases. You had better know all the stories and all the cases before you start spending money buying periodicals on a large scale.

To reenforce our memory at Kraus Periodicals, however, we have a number of aides. One such is a file of "publishers' reports" on several thousand periodical titles. This file is just what its name implies: information from various publishers regarding their particular publications. The specifications supplied by the publishers are kept up to date by annual revisions, there being an employee of our company who does almost nothing else but keep the file current and constantly increasing. The reports themselves contain an enormous amount of information for any given publication: what volumes, issues an $l$ indexes are out of print; what the in-print parts cost; what discounts are allowed to dealers; what current subscriptions cost, although we do not handle subscriptions at all; in some few cases, inventory figures for the in-print parts; a schedule of dates for all previously published volumes; all pertinent bibliographical information, including title changes, suspensions, number of issues per volume, general indexes published, and even the disposition of the title-pageindex. In short, we have a complete case history of almost every title that we handle. Without it we could not operate.

Another important instrument used in buying is our file of dealers' catalogs, which is one of the most comprehensive collections of this type of material ever assembled anywhere. Here are found representative catalogs and lists of every important book and periodicals dealer in the world, dating back to the nineteenth century. The value of these catalogs to us should, I think, be obvious. First, they contain bibliographical and descriptive information sometimes not found anywhere else. (American librarians have failed fully to recognize the importance of these catalogs as a reference tool. There are too few relatively complete files of dealers' catalogs in this country.) Secondly, they provide suggested sales prices, which although at times may be obsolete, nevertheless are all we have to go on. Unfortunately, there is nothing for the periodicals field comparable to Book-Auction Records and Book-Prices Current. Third, they delineate price levels which serve as guides in purchasing, for one does not buy a set for more money than he finds indicated in a competitor's catalog. Of course, where a specific set has become extremely scarce, or there is 
a customer searching for a title where price is of no consequence, then the "established" price is meaningless. You simply "establish" a new price for that title in your own next catalog. But it is more often and likely the case that you will attempt to stay within the bounds of the "going" prices.

The entire question regarding prices and pricing is entirely too complex and specific a problem to be discussed now. Let it be sufficient to say, however, that apart from those principles discussed above, there is always present that one statute of classical economics that governs our entire price determination policy: the law of supply and demand. That is not to say pricing "what the traffic will bear," but rather, in reverse, what it costs to purchase material in the face of the fiercely competitive buying market that exists today. It should be clearly understood that prices for sets of periodicals have risen mainly because it is more costly now to purchase those sets than it was previously. (The other reasons are, obviously, increased costs in handling, storing, and marketing.) The periodicals dealers' current dilemma, as many librarians are aware, is not the pressing necessity of selling his stock as much as the difficulty of being able to replenish it.

The last important piece of auxiliary apparatus used in our buying program is our own reference library. We have assembled, for all who need to consult it, an excellent collection of books about books and periodicals. It is a library that is used constantly and intensively. Indeed, there is a story of long standing in our firm that before an executive can be considered worthy of this name he must have kept in his bedroom for at least a year the Union List of Serials, and studied it nightly before retiring as any theologian would reflect upon his Bible. This anecdote is indicative of two things: how highly we regard reference books in general and the Union List of Serials in particular, and what trials one must endure to attain executive status in a large periodicals company.

Included in this collection of reference books, in addition to the aforementioned Union List of Serials, are such works as the World List of Scientific Periodicals, Ulrich's Periodicals Directory, Library of Congress Catalog of ....Printed Cards, British Museum Catalogue of Printed Books, Bibliotheque Nationale Catalogue Général, Deutsches Bücherverzeichnis, Annuaire de la Presse Française, Schweizerischer Zeitschriften- und Zeitungskatalog, and many, many others. It is doubtful whether any reference collection in any library receives more use than ours.

\section{BUYING-SOURCES}

The question most asked by visitors to our warehouses both here and abroad is: "where does all this material come from?" The answer is no secret: "from many places." There are actually five main sources of supply: (1) libraries, (2) individuals, (3) other dealers, (4) publishers' stock, (5) acquisition of smaller companies.

1. Libraries-The types of libraries to whom we sell are the same types of libraries from whom we buy. The methods of buying from these various types, how. ever, are as dissimilar as the methods of selling to them.

a) Industrial libraries provide us with our current scientific and technical material, which we usually purchase on an "evaluation" basis. Industrial librarians, guided by economy-conscious purchasing agents, know that they ultimately make as much money from their duplicates (with many less headaches) by sending in their journals for evaluation as they would by listing them. Detailing hundreds and thousands of issues involves an inordinate expenditure of effort that is, in the final analysis, uneconomical. In using the phrase "economy-conscious" I did not intend any pejorative connota- 
tion. Rather, through experience, these industrial people know that labor costs a good deal of money today, more, in fact, than could be recouped from the sale of the journals if listed.

Actually, in a large periodicals company such as ours, there is very little difference in the amount that would be paid if we "bid" on the duplicates or if we "evaluated" them. The reason is, simply, that every title and virtually every volume within that title carries predetermined purchase and sales prices. There is no sentimentality or favoritism among the members of our receiving department for General Electric over Westinghouse or the Bell Telephone Laboratories over IBM. Besides being more economical for the senders, the "evaluation" method is more economical for us, saving the expense of initially preparing the bid and then the ensuing correspondence resulting from it. There are times, of course, when the arrangement proves unsound for us; that is, when the majority of the journals sent in for evaluation is found to be waste paper. After all, there are shipping charges and the expenses of labor for unpacking and sorting the material. If we discover this to be the case after two or three shipments, then we simply request the shippers to refrain from sending us their duplicates. The entire situation is comparable to the "gifts" problem of libraries.

For the most part, the material received from the industrial library is scattered; sets and long runs are the exception rather than the rule. Occasionally, however, sets are offered in collections resulting from the merging of two companies and an overlapping of the two libraries' holdings, the discontinuance of a division of a company and a dimunition of interest in the specific subject area of that division, or an exhaustion of space and a decision to discard specific back files in favor of current holdings. When collections are disposed of, for any of these reasons, they are usually offered for sale on a bid basis.

b) The college and university libraries' duplicates that are sent or offered to us are usually in the form of longer runs and sets. Single issues and scattered volumes apparently are disposed of elsewhere: sometimes to the United States Book Exchange, less often to a regional or local exchange union, most often to the wastepaper dealer, occasionally to those periodical dealers who issue buying lists. We do receive from several university libraries shipments of miscellaneous material, but the emphasis is more on the liberal arts than the sciences, as is the case of the industrial library.

Generally this type of library prepares lists of all its duplicates-issues and volumes along with sets. The practice is to circulate the lists among several dealers asking for bids and the conditions of purchase: i.e. who pays shipping charges, whether the material can be used as credit against future purchases, by what methods the material may be shipped, or other factors. When the bids are returned and evaluated, a decision is reached and the successful bidder informed. Ironically, it seems that the single issue and volume lists are prepared with great care and apparent effort, whereas the offers of long runs and sets are often appended with such ambiguous declarations as "an almost complete set" or "complete except for a few lacking issues" or "we believe complete, although it has not been collated." From experience we know that when such statements are made the runs or sets are almost never complete, and that the "few issues" that are missing are among the most difficult of that title to find.

On the other hand, many inventories are quite carefully prepared and are nearly professional-looking in their presentation. The Cornell University Library and the Medical Library of Columbia University, to mention only two 
that come to mind immediately, issue monthly lists (rather than irregular ones, which is the case with most libraries) that meet the above specifications. It is interesting to note, by way of comparison, that the duplicates offered by the former library are almost exclusively short, incomplete sets that are weeded from the collection, whereas the latter sells only the longer and more complete sets that are received as gifts. Further, they both request cash payment, which is contrary to the customary university library request for credit.

c) The material that we purchase from the public libraries in this country are generally in collections, and often large ones at that. Obviously, the journals (more properly magazines) to which the smaller and medium sized public libraries subscribe are not of the type that we normally acquire. However, the larger libraries, often cramped for and desirous of extra space and funds, do offer for sale groups of sets that they have assembled over the years and which are perhaps now felt to be extraneous to their needs.

An outstanding example of this is the excellent collection that we purchased recently from the Allegheny Regional Branch of the Carnegie Library of Pittsburgh. Once an important science and technology library, supporting and being supported by the research programs of the surrounding industrial companies of Pittsburgh, this collection fell into disuse over the years when the Westinghouse, General Electric and U. S. Steel established their own libraries. The branch was, of course, still being used when the sale to us occurred. However, the local, lay reader was little impressed by nor had much need for the complete sets of American Journal of Science, Botanical Gazette, Astrophysical Journal, International Catalogue of Scientific Literature, Journal of Geology and Journal of Physical Chemistry that stood on the shelves. The directors, therefore, very wisely decided to dispose of this material.

Thus, in a highly competitive bid conducted among six dealers did we purchase, for "over $\$ 50,000, "$ all of the scientific and many of the liberal arts journals of the Allegheney Regional Library. The beauty of the collection was that every volume was complete, bound, and in excellent condition, and almost every set was intact from volume 1 to date. We think it was worth every penny that we paid for it.

In any one year two or three public library collections such as this will be offered for sale. We wish there were more.

2. Individuals-Purchases made from individual collectors are usually small, relatively unimportant, but often provide us with the cleanest material that we receive. The reasons are, of course, that personal holdings get far less use than library copies, and that they are cared for a great deal more. The "individuals" referred to come from all walks of life, but most often they are retired professors, industrial scientists or engineers, or other types of active researchers.

Another large group are the wives of these journal-savers; it appears that one of the very first decisions the wife of a deceased collector makes is to sell his books.

My remarks about inaccuracies in the listings by librarians can be multiplied in volume and degree when applying the same matter to purchases from individuals. Indeed, we have learned from experience not to expect anything approaching the material that was originally offered. It works, to be sure, both ways: at times we are pleasantly surprised at how much extra we receive, although most of the time we are shocked by the lacks. But in the long run the additions and the shorts balance out each other, and it is very seldom that we will claim anything from an individual. There is, really no particular point in claiming: the ensuing reply is invariably 
that "the material was packed personally by me," and an error, therefore, is "out of the question."

If I appear to be a little derisive or ridiculing in my remarks concerning individuals who sell their journals, let me halt that impression immediately. Actually, I have meant to be sharply contemptuous, for I generally consider many of these people to be the most harmful of all to the libraries of the world. The reason for my contempt lies in the fact that whereas the hoarder of journals preciously guards the condition of his material, he even more fastidiously searches for ways to dispose of it unethically. Libraries for the most part offer their surplus periodicals for sale on a closed-, single-, unalterable-bid basis. Not so, however, those individuals who do not abide by the rules of the game but delight in the auction that ensues when they indicate (ever so delicately) that your competitor has already entered a bid ten percent higher than you and wouldn't you therefore care to reconsider. The wheels are set in motion when this same information is hinted to three or four dealers simultaneously. When the material is of little importance we customarily ask the seller to forget the entire matter and we withdraw our original bid from consideration. However, where the collection is important, we become involved in the auction along with everyone else.

I not only consider this type of selling unethical but inconceivably detrimental to the interests of the library world. For who, after all, pays the increases in the purchase price when the collection goes "to auction"? Certainly not the dealer, who works on a fixed margin of profit. When the price goes up in the buying of a set, then the price is proportionately increased when it is sold. This factor, as stated above, is one of the principal reasons for the increase in prices of sets of periodicals.

3. Other Dealers-When a new list or catalog is issued by another periodicals dealer we generally try to read it immediately. It is read with extreme care for a number of points: a comprehensive picture of the level of prices, the inclusion of specific sets that are known to be required by certain libraries, the listing of odd volumes which may possibly complete sets that are presently incomplete in our own stock. Almost every mail brings a new list from some dealer somewhere in the world, and the reading program is understandably an enormous one. I would conservatively estimate that I read (in varying degrees of thoroughness) some 350 dealer catalogs a year. Other people on our staff probably read a total of 500 more.

The cooperation among dealers is, for the most part, good. There are two or three in the world, however, who refuse to sell to other dealers. (There is, apparently something sacrosanct about a library purchase order!-and, besides, they don't have to extend to libraries that usual courtesy, the $10 \%$ discount, offered to other dealers). Cooperation is, of course, a two-way proposition, and we assist other dealers with the same general degree of enthusiasm that is exhibited towards us.

There are hundreds of smaller dealers throughout the world who do not issue catalogs at all. From these people we usually buy as a result of direct offers or visits. With the same regularity that the mail brings catalogs, it also brings offers from unknown (to the library world) Japanese, Italian, Mexican, Argentinean or Czechoslovakian dealers. Many of these people are almost amateurs at their trade; for example, very few of them know the real value of the material they are offering. Most of the time the asking prices are exorbitantly high or ridiculously low; generally they are based upon the prices that were paid for the material. Many of the obvious novices ask us to set the prices ourselves. In this manner, thousands upon thousands of vol- 
umes are purchased by us, and hundreds of people who "dabble in books" earn a living.

The reasons that the smaller dealer sells his journals to us, rather than retaining them himself, are obvious: (1) he cannot afford, because of limited capital, to keep his stock inactive for very long; (2) he does not generally have close contact with the libraries of the world, nor can he afford the expensive marketing procedures followed by the larger dealers; (3) he does not have the space to store nor the staff to process a large amount of material. In the interest, therefore, of a quick-but necessarily lesser-return on his investment, the small dealer disposes of the stock which he cannot, for various reasons, maintain.

Besides buying from direct offers, we also buy a considerable amount of material through periodic "scouting" or "field" trips, both in this country and abroad. At the present time, I would say, we spend more money and energy on buying than on selling trips.

There is a great fallacy, however, in the belief, current among librarians, that they can make "buying trips" abroad pay in the same way we do. The main difference lies in the approach and the intent: we buy in quantity and not necessarily in sets. A visit to a dealer's warehouse in London, Paris, or a suburb of Brussels may yield three thousand volumes in German or French Zoologyno ten of which are of the same title, or all of which are of five titles with up to ten copies of each volume. By combining these purchases with our own stock, and by buying judiciously elsewhere in the world of these same titles, we are able to put together multiple and marketable sets. A librarian has not paid for a buying trip abroad in the last 25 years if he has gone to buy periodicals alone. (This is in no way, of course, intended to discourage travel requests. I fully realize that there are other things in life besides periodicals.)
For the most part, then, the hundreds of smaller dealers scattered throughout the world are of importance to American libraries. However, their significance lies chiefly in their role as "stringer" suppliers to, and scouts for, the larger dealers.

4. Publishers' Stock-For the same reasons that smaller periodicals dealers would rather turn over their stock to larger dealers than maintain it themselves so the publishers of periodicals would rather dispose of their back issues. Faced with limited space, little help, small budgets-and often attractive offers from a periodicals dealer-the publisher is delighted to relieve himself of the responsibility of being in "the back issues business."

The recent tendency of acquiring publishers' stock has been implemented and expedited by the establishment, by many of the larger corporations, of reprint affiliates. It is usual, when signing a reprint contract with a publisher, to purchase those back issues that are still inprint within the inclusive volumes that will be reprinted. Thus, when we agree recently with the American Anthropological Association to reprint volumes 1 through 50 of the American Anthropologist, we also purchased from the Association the few hundred issues that were on hand, at an agreed per issue price, between volumes 1 and 50 .

Although the idea of acquiring complete control of a title, usually an important title, may appear to be a splendid and profitable idea, it may seem less splendid upon further analysis, and infinitely less profitable as a result of some disappointing experiences. Actually, every dealer who has been actively buying publishers' stock during the past five years-the period of the greatest activity in this area-has warehouses bulging today with thousands upon thousands of copies of identical issues and volumes. The Stechert-Hafner Company, for example, recently signed a contractual 
agreement with the New York Botanical Garden (an arrangement, by the way, much sought after by several dealers, including ourselves) whereby they would reprint the out-of-print parts of the various publications of that society. But along with the reprint rights they also inherited some 100,000 issues of Economic Botany, Mycologia, Addisonia, Brittonia, North American Flora, and the Memoirs of the New York Botanical Garden. We did no better during the past year, receiving some 70,000 issues of the Publications of the Modern Language Association, when we agreed to reprint the first 30 or so volumes of PMLA.

I believe that the entire program of acquiring this stock from the publishers is a foolish enterprise for the dealers. They inherit the same problems that the publishers had, on top of having to invest additional capital. But in an industry that is already highly competitive, it is a necessary device of self-protection to acquire the obviously important titles before your competitors do. It must be apparent that if one dealer controlled all the stock of most of the best-selling journals, there would be little possibility of real co-operation. Only by having something to offer can you expect other companies to fill your requests. And as a corollary to this, it should be noted that the stock could fall into undesirable hands, where an unscrupulous person could demand unreasonable prices. Thus, the reputable dealers are performing a service to the library world by protecting libraries, as well as themselves, against such a possibility.

Up to the present time, my own company has purchased the publishers' stock of approximately fifty important periodicals. Involved are hundreds of thousands of issues and many thousands of dollars. It is a terribly expensive prestige activity. 5. Acquisition of Smaller CompaniesThe main physical growth of Kraus Periodicals, Inc. has resulted from the purchase of several smaller companies and the merging of their stock into our own holdings. Apart from many minor mergers, the most important acquisitions were Universum Book Export Company (1951), B. Login and Son, Inc. (1953), and the periodicals department of the $\mathrm{H}$. W. Wilson Company (1955). Nor have we been alone in this program of buying up smaller companies. Within the past few years one of the oldest companies in the United States in this field, the periodicals department of the F. W. Faxon Company of Boston was purchased by the J. S. Canner Company (1957). Less than two years ago one of the most respected, the AshleyRatcliff Corporation of New York, was purchased by Walter J. Johnson, Inc. (1958). There are many more examples, too numerous to mention here.

Despite the loss of these companies, however, the industry as a whole has grown. The recent replacements, to be sure, have been one man operations, mainly products and ex-members of the major companies. But they represent the possible large companies of the future. Sol Grossman, former manager of Zeitlin and Ver Brugge, established Western Periodicals in Los Angeles about three years ago; Alfred Jaeger, a former executive of the Walter J. Johnson, Inc. began operating a business under his own name about two years ago in New York; another executive previously of the Johnson organization, Gerhard J. Meier, also founded a company in New York last year; a fourth example is Harold Burstein, formerly with J. S. Canner Company, who organized a firm about two years ago in a suburb of Boston. There are others, and there will probably be many more in the future.

The main problem facing these and similar companies is their lack of funds with which to support and, in fact, to build an adequate stock. Immediately upon acquiring a good set or run, they usually sell it at a "wholesale" price to one of the larger dealers in order to meet current obligations. Conversely, having 
little stock themselves, they are forced to purchase from these same dealers at only slightly below "retail" prices those sets which they are able to sell. There is little possibility for real growth operating under these conditions.

Everyone, however, wishes them well and hopes that they, too, do not become additional "small company casualties".

\section{Buying-The Future}

Several dealers have indicated that the sources of supply are drying up. The few good sets that do become available, the argument goes on, are immediately purchased by libraries and thus taken out of circulation forever. Furthermore, there are not enough private sources from which to buy to accommodate the everincreasing demands of the existing libraries, to say nothing of the newly established ones. The picture for the future, as painted by these cynics, is dismal.

These assumptions, for the most part, are utter nonsense. First, the established libraries in this country, which still account for the majority of our annual business, have already purchased the standard English-language periodical sets. In fact, they began long ago acquiring the secondary foreign-language journals.

To prove this premise, which we had already suspected to be true, a rather costly experiment was conducted. We issued our "Acquisitions Bulletin No. 12," covering exclusively the fields of Englishlanguage biology and medicine, during a prime sales period (September, the beginning of the school, and in most cases the fiscal, year). From the standpoint of its content and production the catalog was a good one; from the aspect of its sales accomplishments it was an abysmal failure. Whatever sales were made from the catalog were almost exclusively abroad-in India, Japan, and South America. Considering that the main volume of the Union List of Serials alone contains almost 120,000 serial titles, there is still a considerable amount of material to be bought and sold, other than the basic English language sets.

The second point in deflating the pessimists' arguments is that reprints are more than sufficiently furnishing the requirements of the newer libraries for the more common titles. These reprints can, of course, be issued in any required number, and the editions are usually adequate. As I have stated previously, many of the larger dealers (Dawson, Johnson, Kraus, Stechert) have already established reprint affiliates and hundreds of the more important titles have since been reprinted or are in various stages of preparation. The reprint program is, however, a separate paper in itself, and will be dealt with accordingly.

Third, it is not entirely true that a periodical set is taken out of circulation once it is placed in a library. As pointed out above, many industrial and public libraries dispose of files, and, indeed, entire collections that are felt to be extraneous to current needs. This is also essentially true of many college and university libraries, who are constantly weeding their collections and revising their requirements. Further, due to the ever-increasing use of microcards and microfilm, sets are released for sale when replaced by these and other forms of microtext. Thus, as I have tried to point out repeatedly in this article, libraries, not individuals, are the single most important source of our material.

It is, of course, true that all dealers are constantly searching for new sources of supply. In the future we will all have to try a little harder to find those untapped resources. With demand constantly increasing, our buying concepts and methods will have to be revised. We shall have to start "thinking big"-or perhaps bigger. But the fact that many of us are thinking is a positive feature: one which is bound to make life for you, the librarian, a little easier. 